\title{
The Impacts of On-Farm Diversification to the Family Farm and the Intersection with Land Preservation and Public Planning Policy in Ontario
}

\author{
Pam Duesling \\ PhD Candidate - University of Guelph \\ 2021 Rural Research Symposium \\ February 11, 2021
}


"To preserve agriculture, it is not enough to preserve the land; society must also preserve the farmer"

Walton, 2003, p.31 


\section{What my research is all about...}

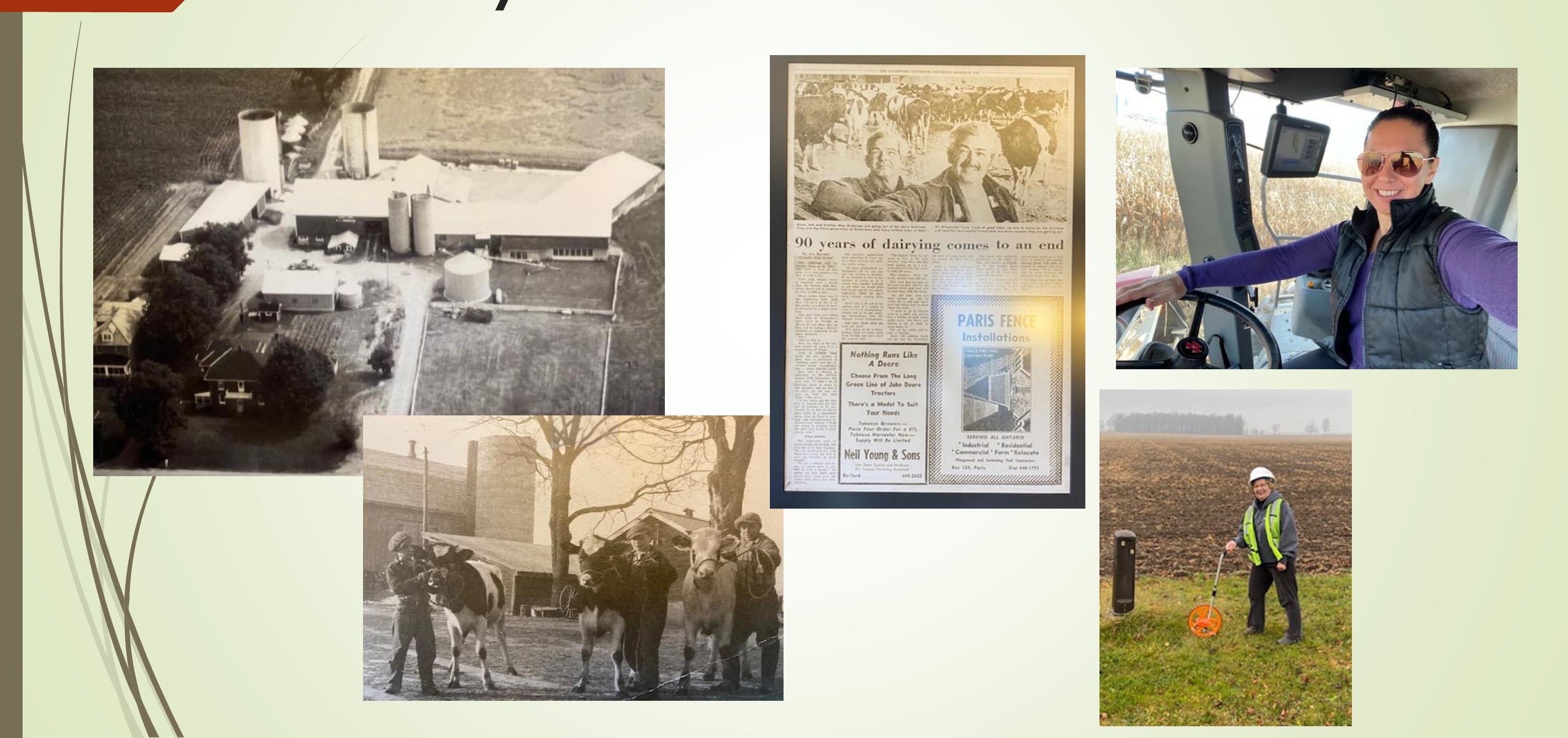




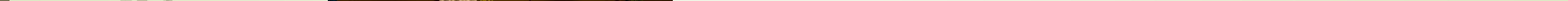




\section{What my research is all about...}

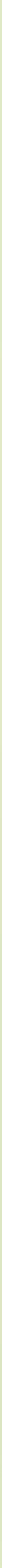




\section{What my research is all about...}

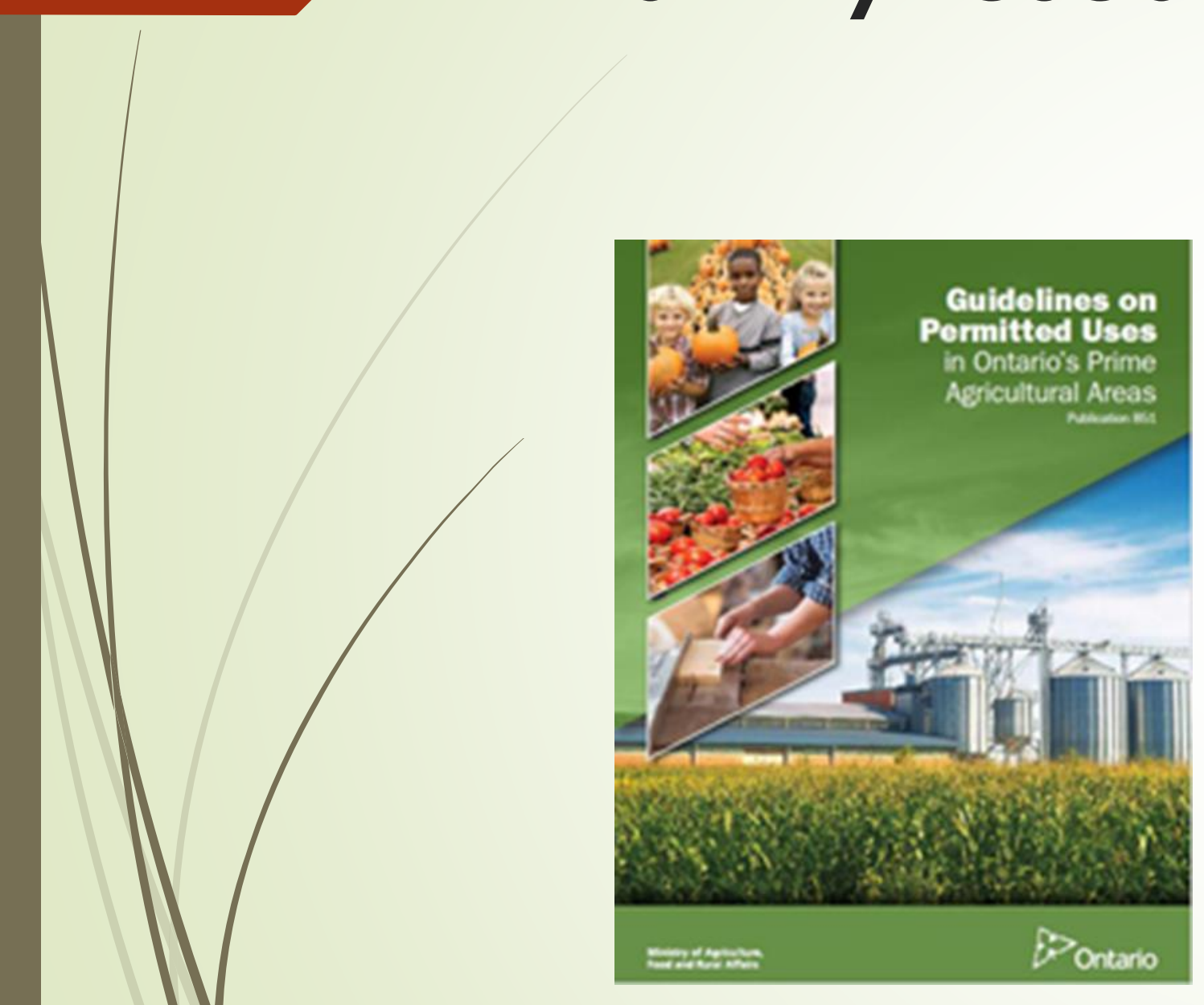

\section{- On Farm-Diversification}

"Uses that are secondary to the principal agricultural use of the property, and are limited in area. On-farm diversified uses include, but are not limited to, home occupations, home industries, agri-tourism uses, and uses that produce value-added agricultural products" Section 2.3 identifies criteria

1) Located on a farm

2) Secondary to the principal agricultural use of the property

3) Limited in area ( $2 \%$ of a farm parcel to a maximum of 1 ha $(10,000 \mathrm{~m} 2)$

4) Includes, but is not limited to, home occupations, home industries, agri- tourism uses and uses that produce value-added agricultural products

5) Shall be compatible with, and shall not hinder, surrounding agricultural operations 


\section{Knowledge Gap}

- Primary Research Objective

To understand how on-farm diversification impacts the family farm and what the intersection of on-farm diversification and land preservation is through public planning policy in Ontario. 


\section{Stakeholders \& Research}

- Who will be interested in this research?

- Family Farmers/ Entrepreneurs

- Provincial / Municipal Governments

- Rural Ontario Residents/ Tourists/ Tourist \& Business Associations

- Global Farmers \& Entrepreneurs/ Governments / Residents/ Tourists/ Business Associations

- How Research will be Conducted

- Survey to Ontario Municipal Planners - SPRING 2021

- Survey to Ontario On-Farm Diversified Farmers - SPRING/SUMMER 2021

- Interview with Provincial Planners - SUMMER 2021

- Interviews with On-Farm Diversified Farmers - SUMMER 2021

- TABULATION OF RESULTS AND FORMULATE RECOMMENDATIONS

- Focus Group with Municipal/ Policy Planners - WINTER 2022

- Focus Group with On-Farm Diversified Farmers - WINTER 2022 


\section{Key Points of Information to Take Away}

- Family farming has evolved and changed over time

- On-farm diversification is rapidly increasing

- Agricultural land preservation is incredible important - especially in terms of prime agricultural lands

- Currently policy regime is confusing and inconsistent in terms of land preservation vs on-farm diversification

- Farmers and Planning Policy need to work together to create a balanced approach to preserve land and provide opportunities for family farms

- My desire is to research, educate and provide policy recommendations for the future 
"The decisions made today will fundamentally affect options available to future generations. The ability to produce food, to regulate the system of production to reflect the values of society, to maintain the important economic contributions of agriculture, and to retain the important role that farmers play in managing the countryside is dependent on retaining farmers and the lands essential to their livelihood"

(Caldwell et al., 2017, p. 61). 